Research Article

\title{
Development from Jasminum sambac Flower Extracts of Products with Floral Fragrance and Multiple Physiological Activities
}

\author{
Li-Chun Wu, ${ }^{1}$ Chieh-Li Lin, ${ }^{2}$ Chia-Chen Peng, ${ }^{2}$ Tzu-Ling Huang, ${ }^{2}$ Teh-Hua Tsai, ${ }^{3}$ \\ Yun-Erh Kuan, ${ }^{2}$ and Ying-Chien Chung $\mathbb{D}^{2}$ \\ ${ }^{1}$ Department of Logistics Engineering, Dongguan Polytechnic, Dongguan 523808, China \\ ${ }^{2}$ Department of Biological Science and Technology, China University of Science and Technology, Taipei 11581, Taiwan \\ ${ }^{3}$ Department of Chemical Engineering and Biotechnology, National Taipei University of Technology, Taipei 10608, Taiwan
}

Correspondence should be addressed to Ying-Chien Chung; ycchung@cc.cust.edu.tw

Received 23 May 2021; Revised 15 July 2021; Accepted 6 August 2021; Published 13 August 2021

Academic Editor: Víctor López

Copyright (C) $2021 \mathrm{Li}$-Chun Wu et al. This is an open access article distributed under the Creative Commons Attribution License, which permits unrestricted use, distribution, and reproduction in any medium, provided the original work is properly cited.

To obtain a potential commercial product with floral fragrance and physiological properties from Jasminum sambac flower extracts, enfleurage was conducted for a short time and followed by further extraction through supercritical fluid extraction (SFE). The product extracted through SFE (called 100\%SFE) exhibited low physiological activity (including 50.7\% antityrosinase activity, $38.6 \%-45.9 \%$ radical scavenging activity, and $6,518-15,003 \mathrm{mg} / \mathrm{L}$ half-maximal inhibitory concentration [ $\mathrm{IC}_{50}$ ] of antioxidant activity) and an intense jasmine-like flavor but was nontoxic to CCD-996SK and HEMn cells. By contrast, the residue (called RO) exhibited high physiological activity (94.2\%-100\%), light jasmine-like flavor, and slight cytotoxicity at the concentration of $4,000 \mathrm{mg} / \mathrm{L}$. When $100 \% \mathrm{SFE}$ and RO were mixed in the ratio $2: 8$, the resultant mixture exhibited $100 \%$ antityrosinase activity, $>91.3 \%$ radical scavenging activity, strong antioxidant activity $\left(\mathrm{IC}_{50}: 273-421 \mathrm{mg} / \mathrm{L}\right)$, high total phenolic content (172.15 mg-GAE/ g-extract), noncytotoxicity, and moderately intense jasmine-like flavor; it is also economically competitive. The major antioxidants in these extracts were revealed through gas chromatography-mass spectroscopy (GC-MS). Additionally, the composition and quality of fragrance were confirmed through GC-MS and sensory evaluation, respectively. The major fragrance components in the $2: 8$ extract mixture were benzyl acetate, $\beta$-pinene, pentadecyl-2-propyl ester, citronellol, jasminolactone, linalool, farnesol, and jasmone. On the basis of the results, we strongly suggest that the $2: 8$ mixture of extracts from $J$. sambac flowers can be a powerful antioxidant, whitening, and nontoxic ingredient that can be employed in the pharmaceutical, cosmeceutical, and food industries.

\section{Introduction}

Jasminum sambac Linn. (Family Oleaceae) (J. sambac) is an erect or scandent shrub, can grow up to roughly $1-1.5 \mathrm{~m}$, and is cultivated throughout tropical and subtropical regions [1]. The flowering stage of $J$. sambac is long in Taiwan (May to October), and thus, this flower can be commercially cultivated in Taiwan for producing value-added products, such as essential oils, in both absolute and concrete forms [2]. The value-added products of J. sambac flowers are used extensively in the manufacture of cosmetics, perfumes, drinks, and consumer goods (e.g., toilet paper, paper tissues, and detergent) [3]. Furthermore, the flowers have been reported to have therapeutic uses in medicine for soothing irritating coughs, alleviating muscular pain [4], and treating dermatitis, diarrhea, conjunctivitis, and abdominal pain [5] as well as preventing breast cancer and stopping uterine bleeding [6]. Moreover, J. sambac flowers are known to have other physiological and pharmacological properties, such as antioxidant, antiaging, skin-lightening, and antibacterial 
activities [7], and no systemic biological toxicity or mortality was observed in tested mice [8]. The essential oils and extracts of $J$. sambac flowers are, therefore, safe as functional ingredients for general use in medicines, cosmetics, and food.

To obtain essential oils, absolute or concrete, from jasmine flowers, different extraction techniques have been employed, such as enfleurage, maceration, and solvent extraction [9]. However, poor product quality is a concern when using these methods because of solvent residues, low physiological activity, impurity, and a distorted smell [10]. Supercritical fluid extraction (SFE) is a rapid, selective, and convenient method and is usually performed with pure or modified $\mathrm{CO}_{2}$ [11]. It has the advantages of low operating temperature, short extraction time, favorable selectivity, high environmental compatibility, and little solvent residue [12]. Thus, SFE is considered one of the most efficient extraction methods in the food, pharmaceutical, and cosmetic industries.

Different extraction techniques, floral stages, and varieties result in different chemical constituents and concentrations in jasmine flower extracts [13]. More than 100 constituents have been identified, but linalool, benzaldehyde, benzyl alcohol, benzyl acetate, $\beta$-farnesene, citronellol, and nerolidol are often abundant in the extracts of J. sambac flowers obtained through SFE, solvent extraction, hydrodistillation, or enfleurage $[1,3,11]$. Furthermore, the variation in the chemical constituents of J. sambac flower extracts is dependent on the geographical origin of the J. sambac - that is, China, Pakistan, India, or Indonesia $[7,11,12,14]$. The extracts have different aromas or various physiological properties, such as antioxidant, antimicrobial, antityrosinase, antitumor, and analgesic activities [15].

Commercially, an extracted product of J. sambac flowers should have both a floral fragrance and physiological properties. Enfleurage is used for preparing aromatic oils; however, it involves a long preparation time (e.g., 12 days) and laborious steps [3]. To solve this problem and obtain an extract with a high-grade aroma, SFE with $\mathrm{CO}_{2}$ is applied $\left(\mathrm{SFE}-\mathrm{CO}_{2}\right)$ [16]. SFE- $\mathrm{CO}_{2}$ is a known extraction method for low-polarity, lipophilic, or low-boiling-point volatile compounds such as aromatic compounds, but it is unfavorable for extracting compounds with polar groups $(-\mathrm{OH},-\mathrm{COOH}$, etc.) [17]. Therefore, compounds with physiological or pharmacological activity-such as those containing polyols, polybasic acids, and polyhydroxy aromatic compounds-are found in small amounts in extracts obtained using SFE- $\mathrm{CO}_{2}$.

To obtain products from $J$. sambac flower extracts that have both high-grade aroma and desirable physiological properties, we prepared $J$. sambac flower extracts by using enfleurage for a short duration (6 or $24 \mathrm{~h}$ ) and further extracted or concentrated the extracts through $\mathrm{SFE}-\mathrm{CO}_{2}$. The physiological properties, cytotoxicity, and chemical constituents of the extracts, residual oils, and mixture extracts were evaluated. Finally, the floral fragrance of the four types of $J$. sambac flower mixture extracts was evaluated through a sensory test. To our knowledge, this is the first study to develop products from J. sambac flower extracts that have a high-grade aroma and multifunctional activities and that can be used in food, medicine, and cosmetics.

\section{Material and Methods}

2.1. Materials. Fresh J. sambac flowers were collected from agricultural fields (Huatan Township, Changhua County, Taiwan). The species were identified by $\mathrm{Dr}$. $\mathrm{Hu}$ at the China University of Sciences and Technology (CUST), Taiwan. Voucher specimens have been deposited at the Centre for Plant Protection Studies, CUST, Taiwan. Cultures of HEMn cells (Cascade cat. C-102-5C, Cascade Biologics, Inc., Portland, OR, USA) obtained from neonatal foreskin were propagated in medium 254 supplemented with human melanocyte growth supplement (Cascade Biologics, Inc., Portland, OR, USA), and the normal human skin fibroblast cell line CCD-966SK (ATCC CRL-1881) was purchased from Bioresource Collection and Research Centre (Hsinchu, Taiwan). Mushroom tyrosinase (350 units $/ \mathrm{mL}$ ) was purchased from Sigma Chemical Co. (St. Louis, USA). All chemicals used in the current study were of analytical grade.

2.2. Extract Preparation. The J. sambac flowers were washed with distilled water to remove dirt on petals. Petals were separated from sepals, weighed, air-dried at room temperature, and then used in extraction. In the extraction, approximately $30 \mathrm{~g}$ of flowers was subjected to maceration with $300 \mathrm{~mL}$ of canola oil at room temperature for 6 or $24 \mathrm{~h}$ and then centrifuged at 3,000 rpm for $15 \mathrm{~min}$; the products obtained were called $5 \%$ oil extract (called $5 \% \mathrm{OE}$ ) and $20 \%$ oil extract (called 20\%OE), respectively. Afterward, the $20 \%$ OE product was placed into the extractor of the SFE apparatus (Separex, France), and supercritical $\mathrm{CO}_{2}$ extraction was performed. The extraction was conducted at 200 bar pressure and $35^{\circ} \mathrm{C}$ on the basis of the method detailed by Younis et al. [11]. In the separator of the SFE apparatus, $\mathrm{CO}_{2}$ vapor was released, leaving the extract free from $\mathrm{CO}_{2}$, and the extracted compounds (called 100\%SFE) were collected in a flask. Furthermore, the residues in the extractor (called RO) were collected. To obtain potential commercial products (PCPs) with floral fragrance and physiological properties, 2,000 mg/L 100\%SFE and $4,000 \mathrm{mg} / \mathrm{L} \mathrm{RO}$ were mixed in various ratios: $1: 9,2: 8,3: 7$, and $4: 6$.

2.3. Tyrosinase Activity Measurement. The mushroom tyrosinase activity of the $J$. sambac extracts-5\%OE, $20 \% \mathrm{OE}$, RO, 100\%SFE, and PCPs-was measured through a modification of the method of Wang et al. [18]. First, $10 \mu \mathrm{L}$ of the extract was mixed with $65 \mu \mathrm{L}$ of L-tyrosine $(0.03 \%), 105 \mu \mathrm{L}$ of phosphate-buffered saline ( $\mathrm{pH} 6.8$ ), and $20 \mu \mathrm{L}$ of tyrosinase solution in a 96-well microplate and incubated at $25{ }^{\circ} \mathrm{C}$ for $30 \mathrm{~min}$ in the dark. Before and after incubation, the absorbance of the reaction solution was measured at $490 \mathrm{~nm}$ using an Epoch ELISA reader (Bio-Tek Instruments, Winooski, VT, USA). Kojic acid and $\alpha$-arbutin were used as positive controls. All experiments were conducted in triplicate. The antityrosinase activity of the tested sample was calculated as follows: 
antityrosinase activity $(\%)=\frac{[(A-B)-(C-D)]}{(A-B)} \times 100$,

where $A$ is the absorbance at $490 \mathrm{~nm}$ without extracts (control), $B$ is the absorbance at $490 \mathrm{~nm}$ without extracts and enzymes (blank), $C$ is the absorbance at $490 \mathrm{~nm}$ with extracts and enzymes, and $D$ is the absorbance at $490 \mathrm{~nm}$ without enzymes (blank of $\mathrm{C}$ ). The half-maximal inhibitory concentration $\left(\mathrm{IC}_{50}\right)$ of the extracts was identified as the concentration at which the tyrosinase activity was half its original value.

2.4. Measurement of 2,2-Diphenyl-1-Picrylhydrazyl Radical Scavenging Activity. The 2,2-diphenyl-1-picrylhydrazyl (DPPH) radical scavenging activity of the J. sambac extracts was measured using the method described by Wu et al. [19]. Here, $1 \mathrm{~mL}$ of the extract was mixed with $1 \mathrm{~mL}$ of ethanol (95\%) and $0.5 \mathrm{~mL}$ of DPPH solution $(100 \mu \mathrm{M})$ and incubated at $25^{\circ} \mathrm{C}$ for $1 \mathrm{~h}$ in the dark. Before and after incubation, the absorbance of this reaction solution was measured at $517 \mathrm{~nm}$ by using an ultraviolet-visible (UV-vis) spectrophotometer (Shimizu, Japan). Butylated hydroxytoluene (BHT) was used as a positive control. All experiments were conducted in triplicate. The scavenging activity of the tested sample was calculated as follows:

$$
\text { DPPH scavenging activity }(\%)=\left(1-\frac{A}{A_{0}}\right) \times 100,
$$

where $A_{0}$ is the absorbance of the blank (without extract), and $A$ is the absorbance of the test sample.

2.5. Measurement of 2,2'-Azino-bis(3-Ethylbenzothiazoline6-Sulfonic Acid) Radical Scavenging Activity. The 2,2' -azinobis(3-ethylbenzothiazoline-6-sulfonic acid) (ABTS) radical scavenging activity of the $J$. sambac extracts was measured using the method described by Lee et al. [20]. ABTS cation radical solution was prepared by mixing $7 \mathrm{mM}$ ABTS with $2.45 \mathrm{mM} \mathrm{K}_{2} \mathrm{~S}_{2} \mathrm{O}_{8}(1: 1)$ for $12 \mathrm{~h}$ in the dark and then storing the mixture at room temperature. Before use, the ABTS solution was diluted with methanol until the absorbance at $734 \mathrm{~nm}$ reached 0.7 . Then, $50 \mu \mathrm{L}$ of the extract was mixed with $950 \mu \mathrm{L}$ of diluted ABTS solution and incubated at $25^{\circ} \mathrm{C}$ for $30 \mathrm{~min}$. Before and after incubation, the absorbance of this reaction solution was measured at $734 \mathrm{~nm}$ by using a UV-vis spectrophotometer. BHT was used as a positive control. All experiments were conducted in triplicate. The ABTS radical scavenging activity of the tested sample was calculated as follows:

$$
\text { ABTS radical scavenging activity }(\%)=\left(1-\frac{A}{A_{0}}\right) \times 100 \text {, }
$$

where $A_{0}$ is the absorbance of the blank (without extract), and $A$ is the absorbance of the test sample.
2.6. Measurement of Reducing Power. The ferric reducing power of the $J$. sambac extract was measured using the method described by Fejes et al. [21]. First, $1 \mathrm{~mL}$ of extract was mixed with $2.5 \mathrm{~mL}$ of phosphate buffer $(0.2 \mathrm{M}, \mathrm{pH} 6.5)$ and $2.5 \mathrm{~mL}$ of $\mathrm{K}_{3} \mathrm{Fe}(\mathrm{CN})_{6}(1 \%)$; the mixture was then incubated at $50^{\circ} \mathrm{C}$ for $20 \mathrm{~min}$. After incubation, $2.5 \mathrm{~mL}$ of $\mathrm{Cl}_{3} \mathrm{CCOOH}(10 \%)$ was added to terminate the reaction. After centrifugation at $4,000 \times g$ for $20 \mathrm{~min}, 2.5 \mathrm{~mL}$ of supernatant was collected and mixed with $2.5 \mathrm{~mL}$ of deionized water and $0.5 \mathrm{~mL}$ of $\mathrm{FeCl}_{3}(0.1 \%)$ for $10 \mathrm{~min}$. The absorbance was determined at $700 \mathrm{~nm}$ by using a UV-vis spectrophotometer. Ascorbic acid was used as a positive control. All experiments were conducted in triplicate. The $\mathrm{IC}_{50}$ value was defined as the effective concentration of the extract at which the absorbance was 0.5 .

2.7. $\beta$-Carotene Bleaching Assay. A $\beta$-carotene bleaching (BCB) assay of the J. sambac extracts was performed using a modification of the method of Lee et al. [22]. Briefly, $20 \mu \mathrm{L}$ of $\beta$-carotene solution $(20 \mathrm{mg} / \mathrm{mL})$ was mixed with $1 \mathrm{~mL}$ of $\mathrm{CHCl}_{3}, 40 \mu \mathrm{L}$ of linoleic acid, and $400 \mathrm{mg}$ of Tween 40 in a round-bottomed flask, and the $\mathrm{CHCl}_{3}$ was then removed at $45^{\circ} \mathrm{C}$ in a rotary vacuum evaporator. After evaporation, $100 \mathrm{~mL}$ of distilled water was added, and the mixture was stirred in a sonicator. The resulting solution of volume $2.5 \mathrm{~mL}$ was then mixed with $350 \mu \mathrm{L}$ of extract. The solution was gently shaken and incubated at $50^{\circ} \mathrm{C}$. The absorbance of the solution was measured at $470 \mathrm{~nm}$ by using a UV-vis spectrophotometer every $20 \mathrm{~min}$ until $120 \mathrm{~min}$. BHT was used as a positive control. All experiments were conducted in triplicate. The antioxidant activity was calculated in terms of percentage of inhibition relative to the control by using the following equation:

$$
\text { antioxidant activity }(\%)=\left(1-\frac{A}{A_{0}}\right) \times 100 \text {, }
$$

where $A_{0}$ is the absorbance of the blank (without extract), and $\mathrm{A}$ is the absorbance of the test sample. The $\mathrm{IC}_{50}$ values of the BCB activity of extracts were evaluated at $50 \%$ antioxidant activity.

2.8. Measurement of Ferrous-Ion-Chelating Activity. The ferrous-ion-chelating (FIC) activity of the J. sambac extracts was measured using the method described by Wu et al. [19]. First, $2 \mathrm{~mL}$ of extract was thoroughly mixed with $0.1 \mathrm{~mL}$ of $\mathrm{FeSO}_{4}(2 \mathrm{mM})$. After $30 \mathrm{~s}, 0.2 \mathrm{~mL}$ of ferrozine solution $(5 \mathrm{mM})$ was added, and the mixture was shaken again, after which it was incubated at room temperature for $10 \mathrm{~min}$. The absorbance was measured at $562 \mathrm{~nm}$ by using a UV-vis spectrophotometer. Ethylenediaminetetraacetic acid (EDTA) was used as a positive control. All experiments were conducted in triplicate. The FIC activity of extracts was calculated as follows:

$$
\text { chelating activity }(\%)=\left(1-\frac{A}{A_{0}}\right) \times 100 \text {, }
$$


where $A_{0}$ is the absorbance of the blank (without extract), and $A$ is the absorbance of the test sample. The $\mathrm{IC}_{50}$ values of the FIC activity of extracts were evaluated at $50 \%$ chelating activity.

2.9. Determination of Total Phenolic Content. The total phenolic content (TPC) of the various J. sambac extracts was estimated using a modified Folin-Ciocalteu (FC) colorimetric method and calculated in gallic acid equivalents [19]. Briefly, $1 \mathrm{~mL}$ of extract or gallic acid was mixed with $1 \mathrm{~mL}$ of the $\mathrm{FC}$ reagent (diluted 1/10) in a test tube and reacted at $30{ }^{\circ} \mathrm{C}$ for $10 \mathrm{~min}$. Subsequently, $1 \mathrm{~mL}$ of $20 \% \mathrm{Na}_{2} \mathrm{CO}_{3}$ solution was added to the mixture, which was allowed to react for $60 \mathrm{~min}$ in the dark. The absorbance was then measured at $725 \mathrm{~nm}$ by using a UV-vis spectrophotometer. The calibration curve of absorbance $(y)$ versus concentration of gallic acid $(x)$ was found to be $y=0.0501 x+0.0647$ $\left(R^{2}=0.9968\right)$. The TPC was expressed as the gallic acid equivalent (mg-GAE/g-dried extract).

2.10. Determination of Total Flavonoid Content. The total flavonoid content (TFC) of the J. sambac extracts was estimated using a modified version of the aluminum chloride colorimetric method and calculated in catechin equivalents [23]. Briefly, $1 \mathrm{~mL}$ of extract or catechin was mixed with $300 \mu \mathrm{L}$ of a $5 \% \mathrm{NaNO}_{2}$ solution and $4 \mathrm{~mL}$ of distilled water at $25^{\circ} \mathrm{C}$ for $5 \mathrm{~min}$. Subsequently, $300 \mu \mathrm{L}$ of $10 \% \mathrm{AlCl}_{3}$ solution, $2 \mathrm{~mL}$ of $1 \mathrm{M} \mathrm{NaOH}$, and $2.4 \mathrm{~mL}$ of distilled water were added sequentially to the solution, which was then left at $25^{\circ} \mathrm{C}$ for $15 \mathrm{~min}$. The absorbance of the solution was read at $510 \mathrm{~nm}$ by using a UV-vis spectrophotometer. The calibration curve of absorbance $(y)$ versus concentration of catechin $(x)$ was calculated as $y=0.0429 x+0.0261\left(R^{2}=0.9972\right)$. The TFC was expressed as the catechin equivalent (mg-CAE/g-dried extract).

\subsection{Analysis of the Chemical Composition of the J. sambac} Extracts. The various J. sambac extracts were subjected to gas chromatography-mass spectroscopy (GC-MS) (Agilent GC 7890/MS 5975, USA). To separate the volatile compounds in the extracts, $1 \mu \mathrm{L}$ of a sample volume was injected into the gas chromatograph fitted with HP-5MS capillary columns $(30 \mathrm{~m} \times 0.25 \mathrm{~mm}$ i.d., film thickness $0.25 \mu \mathrm{m})$. Helium was a carrier gas with a linear velocity of $1 \mathrm{~mL} / \mathrm{min}$ and a split ratio of $10: 1$. The oven temperature program ranged from $50^{\circ} \mathrm{C}$ to $300^{\circ} \mathrm{C}$, programmed at $10^{\circ} \mathrm{C} / \mathrm{min}$, with initial and final hold times of $3 \mathrm{~min}$. The interface temperature was $260^{\circ} \mathrm{C}$, and the ion source temperature was $280^{\circ} \mathrm{C}$. Electron impact mass spectra with ionization energy $70 \mathrm{eV}$ were recorded in the $40-600 \mathrm{amu}$ mass range. The chemical compositions of the extracts were identified through a comparison of the mass spectrum of the module with that of the mass spectral library from Wiley 8.0 (Wiley, New York, USA) and NITS 11 (National Institute of Standards and Technology, Gaithersburg, USA). The relative quantities of the compounds were determined through the integration of the peak area in the chromatogram.
2.12. Cytotoxicity Assay of the J. sambac Extracts. The cytotoxicity effects of the J. sambac extracts on CCD-966SK and HEMn cells were assessed using the 3-(4,5-dimethylthiazol-2-yl)-2,5-diphenyltetrazolium bromide (MTT) method [24]. After $24 \mathrm{~h}$ of incubation, the cells of density $5 \times 10^{6}$ per well (96-well plate) were washed using a fresh medium and then treated with $J$. sambac extract or the culture medium (control) for $72 \mathrm{~h}$. The treated cells were then rewashed and reacted with $0.02 \%$ MTT solution at $37^{\circ} \mathrm{C}$. After $4 \mathrm{~h}$ of MTT treatment, the medium was removed, and the precipitate in each dish was dissolved in $100 \mu \mathrm{L}$ of dimethyl sulfoxide. The absorbance of the supernatant was measured at $570 \mathrm{~nm}$ by using an Epoch ELISA reader. The amounts of viable cells after each treatment were expressed as the percentage of the control and calculated using the following formula:

$$
\text { cell viability }(\%)=\left(\frac{A}{A_{0}}\right) \times 100,
$$

where $A_{0}$ is the absorbance of the blank (without extract), and $\mathrm{A}$ is the absorbance of the test sample.

2.13. Sensory Evaluation. In total, 30 trained panelists (15 men and 15 women) were recruited to perform the sensory evaluation of PCPs derived from J. sambac extracts. These trained panelists were 20-22 years old, healthy, nonsmoking, and without olfactory disorders. To evaluate the fragrance emitted from the mixture extracts, $1 \mathrm{~mL}$ of extract was placed in a white vinyl bottle, with the bottles numbered randomly [10]. Panelists were asked to smell the samples for $1 \mathrm{~min}$. The panelists assigned each PCP to one of five levels (from strongly disliked to strongly liked): very bad, bad, regular, good, and very good. The fragrance content of the PCPs was divided into five levels $(0 \%-14 \%, 15 \%-29 \%, 30 \%-$ $44 \%, 45 \%-59 \%$, and $60 \%-74 \%)$ : very low, low, acceptable, high, and very high.

\section{Results and Discussion}

3.1. Antityrosinase Activity. Figure 1 shows the in vitro antityrosinase activity of the J. sambac flower extracts with various concentrations. The results indicated that the antityrosinase activity increased with increasing concentrations of the $J$. sambac flower extracts. The maximum antityrosinase activity increased in the following order: $\mathrm{RO}$ $(100 \% \pm 0.2 \%)>20 \% \mathrm{OE} \quad(78.2 \% \pm 2.5 \%)>5 \% \mathrm{OE}$ $(61.3 \% \pm 3.2 \%)>100 \%$ SFE $(50.7 \% \pm 1.8 \%)$. The $\mathrm{IC}_{50}$ values for RO, 20\%OE, 5\%OE, and 100\%SFE were 263.5, 618.3, 1283.7, and $3986.5 \mathrm{mg} / \mathrm{L}$, respectively. By contrast, the $\mathrm{IC}_{50}$ values of the antityrosinase activity for the positive controls $a$-arbutin and kojic acid were 306.4 , and $26.2 \mathrm{mg} / \mathrm{L}$, respectively. Tyrosinase is the key enzyme for melanin formation. Excessive melanin formation in the skin may cause hyperpigmentation disorders [25]. Thus, a natural and effective tyrosinase inhibitor not only meets the demand for skin-whitening products but also lays the foundation for drugs for treating hyperpigmentation. Few studies have focused on the potential of the antityrosinase activity of 


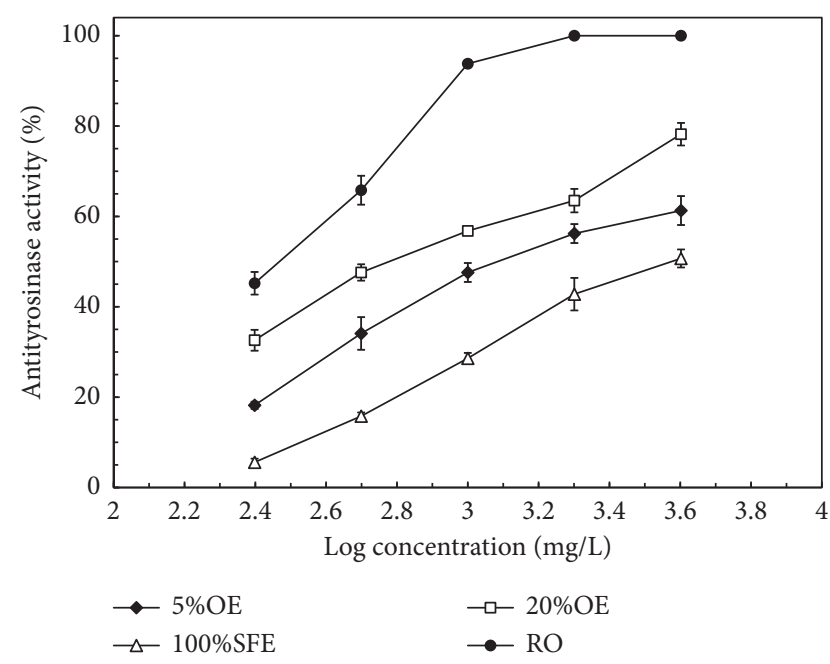

FIGURE 1: Effects of the concentrations of J. sambac flower extracts on mushroom tyrosinase activity. Data are expressed as the means \pm standard deviations of 3 independent experiments.

J. sambac flower extracts. Wang et al. found that the $\mathrm{IC}_{50}$ of the ethanolic extract of J. sambac flowers reached $1,600 \mathrm{mg} / \mathrm{L}$ [25]. Thus, the extracts obtained in the present study, except $100 \%$ SFE, had potential skin-whitening properties.

3.2. DPPH and ABTS Radical Scavenging Activity. Antioxidants have been useful in retarding oxidative deterioration of food and cosmetics, and interest in their therapeutic potential for improving health has increased. Recent investigations have evaluated plant products' potential antioxidants against various diseases because chemical antioxidants (e.g., BHA and BHT) have been suspected of being responsible for liver damage and carcinogenesis in laboratory animals [26]. Thus, antioxidant activity is a key pharmacological property, and many pharmacological activities including skin whitening, antiaging, and anticarcinogenic activities originate from this property [27].

Figure 2 shows the DPPH and ABTS radical scavenging activities of the $J$. sambac flower extracts of various concentrations. DPPH radical scavenging activity increased with increasing extract concentration (Figure 2(a)). Radical scavenging activities were significantly affected by $\mathrm{RO}$ concentration. The maximum DPPH radical scavenging activity increased in the following order: $\mathrm{RO}(94.2 \% \pm 1.2 \%)$ $>20 \% \mathrm{OE} \quad(56.3 \% \pm 1.8 \%)>5 \% \mathrm{OE} \quad(52.3 \% \pm 2.0 \%)>100 \%$ SFE $(38.6 \% \pm 1.2 \%)$. The tendency was similar to that of the antityrosinase activity (Figure 1). Figure $2(\mathrm{~b})$ shows the ABTS radical scavenging activity of the $J$. sambac flower extracts with various concentrations. Results indicated that the ABTS radical scavenging activity was positively correlated with the tested concentration. When the concentration was $4,000 \mathrm{mg} / \mathrm{L}$ (log concentration: 3.6 ), the scavenging activity was not at its highest level. The tendency of the extracts to scavenge ABTS radicals was similar to their tendency to scavenge DPPH, but the ABTS scavenging activity was superior to that for $\mathrm{DPPH}$. The $\mathrm{IC}_{50}$ values of
DPPH and ABTS radical scavenging activities of RO were 512.6 and $368.4 \mathrm{mg} / \mathrm{L}$, respectively; by contrast, those of the positive control BHT were 206.3 and $72.5 \mathrm{mg} / \mathrm{L}$, respectively. The methanolic extracts of both Jasminum grandiflorum flowers and $J$. sambac flowers exhibited DPPH radical scavenging activity with an $\mathrm{IC}_{50}$ of 639 and $208 \mathrm{mg} / \mathrm{L}$, respectively $[1,28]$. The DPPH radical scavenging activity of $\mathrm{RO}$ originating from J. sambac was slightly higher than that of the methanolic extract of $J$. grandiflorum but inferior to that of the methanolic extract of J. sambac.

3.3. Reducing Power, BCB Assay, and FIC Ability. Using only a single or simple indicator to evaluate the antioxidant activity of the J. sambac flower extracts would not provide sufficient understanding of the extracts' antioxidant activity due to the lack of specificity and sensitivity of the methods available [29]. Therefore, reducing power, BCB activity, and FIC ability were investigated using different mechanisms to provide reliable data regarding the antioxidant capacities of the flowers.

Table 1 shows the $\mathrm{IC}_{50}$ values of the reducing power, $\mathrm{BCB}$ activity, and FIC activity for the various J. sambac flower extracts. A low $\mathrm{IC}_{50}$ indicates high activity. Different activity tendencies were observed for the three indexes. RO was the optimal solution regarding reducing power and FIC activity, but $100 \%$ SFE was the optimal solution in terms of $\mathrm{BCB}$ activity. In all antioxidant indexes (Figure 2 and Table 1), only the BCB activity tendency was contrary to the trend in the other antioxidant indexes. This was probably because the $\beta$-carotene solution is lipophilic, which makes it favor hydrophobic $100 \%$ SFE products to function. The $\mathrm{IC}_{50}$ values of the reducing power, $\mathrm{BCB}$ activity, and FIC activity for RO and $100 \%$ SFE were $251.5 \pm 23.5,623.8 \pm 21.3$, and $382.0 \pm 18.5 \mathrm{mg} / \mathrm{L}$ and $6,518.2 \pm 351, \quad 125.6 \pm 5.8$, and $15,003 \pm 201 \mathrm{mg} / \mathrm{L}$, respectively. By contrast, the $\mathrm{IC}_{50}$ values of the reducing power, $\mathrm{BCB}$ activity, and FIC activity for the positive controls ascorbic acid, BHT, and EDTA were 61.3, 92.5 , and $20.5 \mathrm{mg} / \mathrm{L}$, respectively. Compared with the $\mathrm{IC}_{50}$ of the reducing power for the methanolic extract of J. grandiflorum $(603.66 \mathrm{mg} / \mathrm{L}), \mathrm{RO}$ derived from J. sambac flower extracts was promising [28]. These results indicate that when our extraction process is employed, J. sambac flower extracts can not only scavenge free radicals (Figure 2) but also efficiently inhibit chain reactions (Table 1 ).

3.4. TPC and TFC. Phenolic substances exhibit healthpromoting activities, including antipathogenic, antiradiation, antitumor, and antioxidant activities [30]. Polyphenols can be classified into four categories: flavonoids, phenolic acids, stilbene, and lignans [31]. Therefore, TPC and TFC should be simultaneously evaluated to understand the antioxidant characteristics of natural plants.

Table 2 lists the TPC and TFC of the various J. sambac flower extracts. The TPC and TFC ranged from $20.65 \pm 0.82$ to $182.36 \pm 9.23 \mathrm{mg}$-GAE/g-extract and $4.65 \pm 0.32$ to $10.35 \pm 1.02 \mathrm{mg}$-CAE/g-extract, respectively. $\mathrm{RO}$ had the highest TPC and TFC, whereas 100\%SFE had the lowest. The TPC and TFC of the J. sambac flower extracts were clearly 


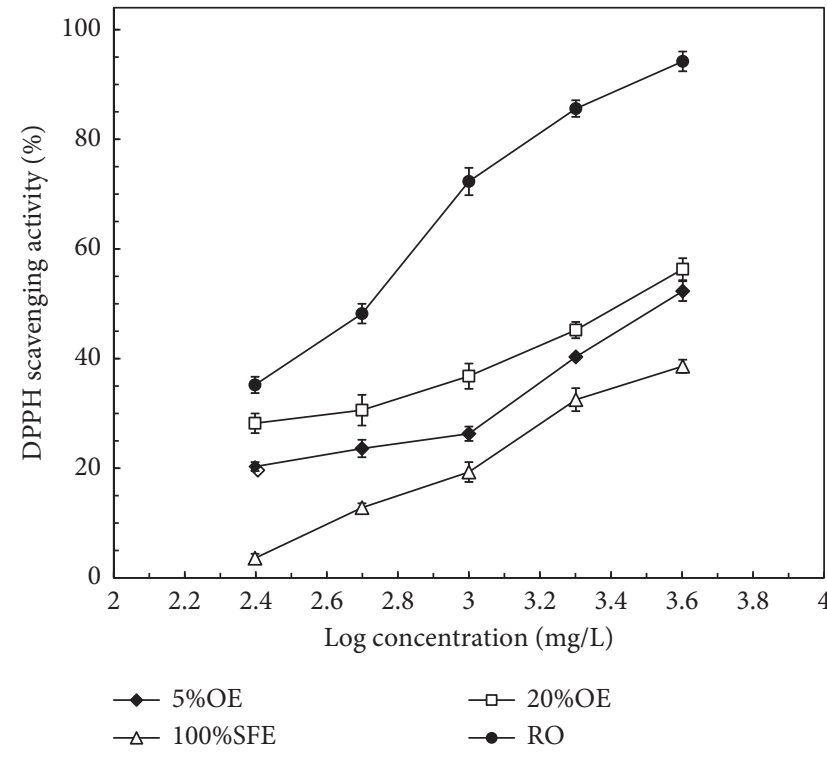

(a)

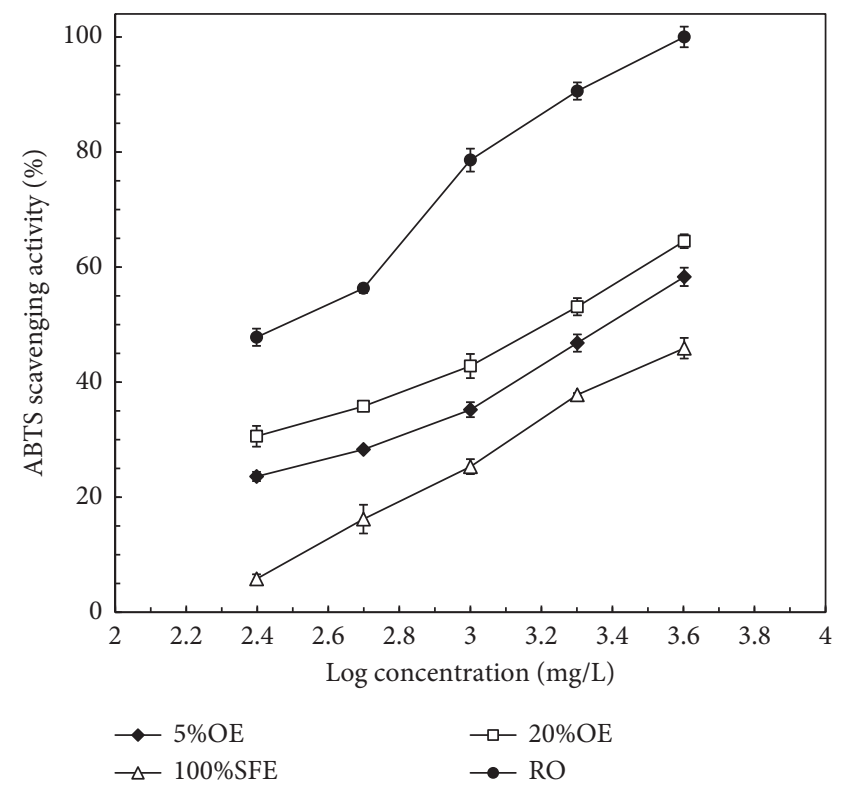

(b)

FIGURE 2: Effects of concentrations on (a) DPPH radical scavenging activity and (b) ABTS radical scavenging activity of J. sambac flower extracts. Data are expressed as the means \pm standard deviations of 3 independent experiments.

TABLE 1: Antioxidant activity (reducing power, $\beta$-carotene bleaching assay, and ferrous-chelating activity) of $J$. sambac flower extracts.

\begin{tabular}{|c|c|c|c|c|}
\hline & $5 \% \mathrm{OE}$ & $20 \% \mathrm{OE}$ & $100 \%$ SFE & $\mathrm{RO}$ \\
\hline Reducing power, $\mathrm{IC}_{50}(\mathrm{mg} / \mathrm{L})$ & $2,017 \pm 135.2$ & $852 \pm 58.1$ & $6,518.2 \pm 351$ & $251.5 \pm 23.5$ \\
\hline$\beta$-Carotene bleaching assay, $\mathrm{IC}_{50}(\mathrm{mg} / \mathrm{L})$ & $356 \pm 35.1$ & $256 \pm 18.2$ & $125.6 \pm 5.8$ & $623.8 \pm 21.3$ \\
\hline $\mathrm{Fe}(\mathrm{II})$ chelating activity, $\mathrm{IC}_{50}(\mathrm{mg} / \mathrm{L})$ & $10,253 \pm 358$ & $1,823 \pm 105.2$ & $15,003 \pm 201$ & $382.0 \pm 18.5$ \\
\hline
\end{tabular}

higher than or equivalent to those of J. sambac flower extracts obtained using acetone/water/acetic acid solvent (20.64 mg-GAE/g-extract and $4.44 \mathrm{mg}$-CAE/g-extract, respectively) [30]. Studies have reported positive correlations between antioxidant capacities and TPC as well as TFC [32]. In this study, the antioxidant capacity of the J. sambac flower extracts was found to be positively related to their TPC and TFC. That is, the more TPC and TFC were, the higher the antioxidant capacity was.

3.5. Cytotoxic Effects. The MTT assay is a common method of evaluating the cytotoxicity of chemical compounds by observing cell viability [33]. Although some studies in the field of cosmetics have evaluated antityrosinase, collagenase, elastase, and hyaluronidase activities and obtained $\mathrm{IC}_{50}$ values of $250-1,600 \mathrm{mg} / \mathrm{L}$ [7,12], cytotoxicity evaluations have not been performed. To ensure user safety, the cytotoxic effects of $J$. sambac flower extracts on human cells should be assessed. Figure 3 shows the effects of the J. sambac flower extracts with different concentrations on the growth of human CCD-966SK and HEMn cells after $72 \mathrm{~h}$ of incubation. At low extract concentrations $(0-1,000 \mathrm{mg} / \mathrm{L})$, cell viability exceeded $98.2 \%$ and cytotoxicity was nonsignificant compared with the control $(P>0.05)$ for all extracts. When the RO concentration was $2,000 \mathrm{mg} / \mathrm{L}$, the viability of CCD966SK and HEMn cells was slightly lower at 93.5\% $\pm 1.2 \%$ and $93.2 \% \pm 0.8 \%$, respectively. When the RO concentration was increased to $4,000 \mathrm{mg} / \mathrm{L}$, clear effects were observed and the viability of CCD-966SK and HEMn cells was decreased to $82.5 \% \pm 1.8 \%$ and $85.2 \% \pm 1.6 \%$, respectively. Although cell viability was affected by RO concentrations 2,000-4,000 $\mathrm{mg} / \mathrm{L}$ compared with the control, RO was not toxic to the cells because cell viability remained $\geq 80 \%$ [34]. The relatively high cytotoxicity of RO may be related to its high physiological activity (Figures 1 and 2 and Table 1). Thus, J. sambac flower extracts are safe for possible applications in the pharmaceutical, health food, and cosmetic industries.

3.6. Effects of the Extract Mixture Ratio on Antityrosinase Activity, Radical Scavenging Activity, and Cell Viability. On the basis of the physiological activity and cytotoxicity results for a single $J$. sambac flower extract and considering floral fragrance and the cost of a single J. sambac flower extract, PCPs were produced by mixing 2,000 mg/L $100 \%$ $\mathrm{SFE}$ and $4,000 \mathrm{mg} / \mathrm{L} \mathrm{RO}$ in various ratios. $100 \% \mathrm{SFE}$ was found not only to have relatively low physiological activity and to be noncytotoxic but also to have the most fragrance and be the most expensive. On the contrary, RO had high physiological activity and relatively high cytotoxicity but the weak scent and was the cheapest. In the SFE procedure, RO is often discarded; hence, the cost of $100 \% \mathrm{SFE}$ is 
TABLE 2: Total phenolic content (TPC) and total flavonoid content (TFC) of J. sambac flower extracts.

\begin{tabular}{lcccc}
\hline & $5 \% \mathrm{OE}$ & $20 \% \mathrm{OE}$ & $100 \%$ SFE & \\
\hline TPC (mg-GAE/g) & $31.21 \pm 1.81$ & $43.65 \pm 2.26$ & $20.65 \pm 0.82$ & $182.36 \pm 9.23$ \\
TFC (mg-CAE/g) & $6.32 \pm 0.18$ & $8.14 \pm 0.45$ & $4.65 \pm 0.32$ & $10.35 \pm 1.02$ \\
\hline
\end{tabular}

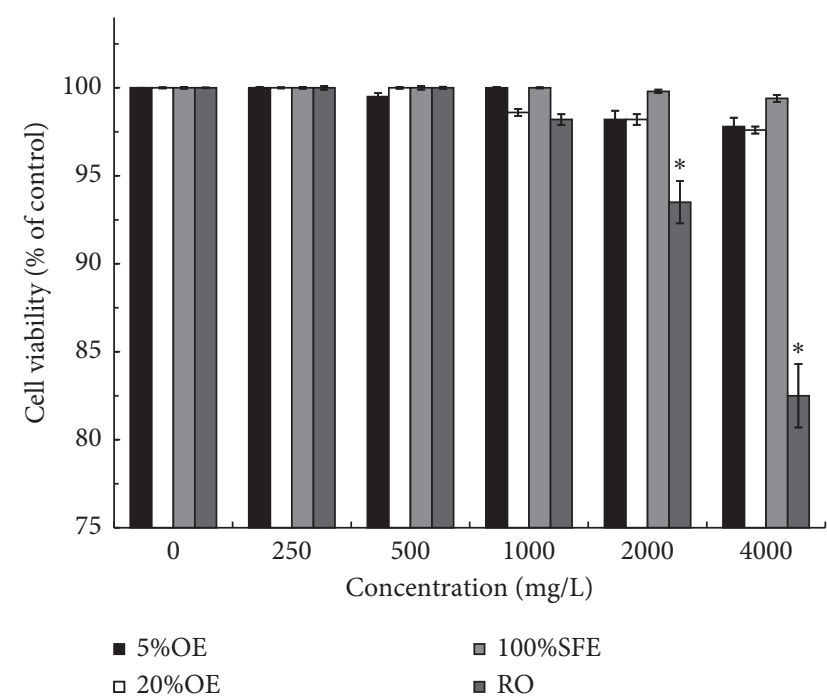

(a)

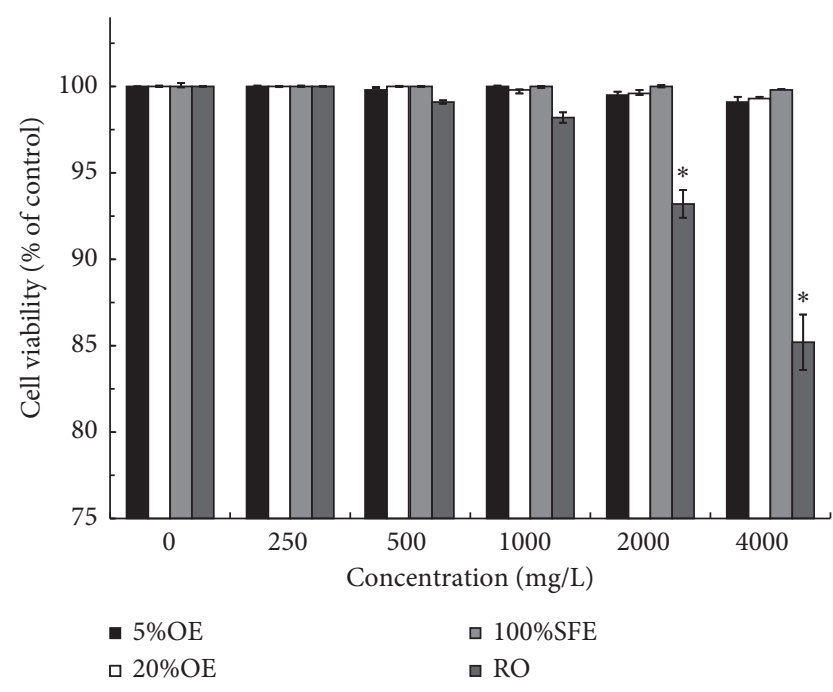

(b)

FIGURE 3: Cell viability of (a) CCD-966SK cells and (b) HEMn cells treated by J. sambac flower extracts with various concentrations for $72 \mathrm{~h}$. Data are expressed as the means \pm standard deviations of 3 independent experiments $\left({ }^{*} P<0.05\right.$ versus blank control).

approximately 10-20 times that of RO. Figure 4 shows the effects of mixture ratio on antityrosinase activity, radical scavenging activity, and cell viability. The effects of $100 \%$ SFE and $\mathrm{RO}$ in various ratios on antityrosinase activity were nonsignificant $(P>0.05)$ except that at the 4:6 mixture ratio, the antityrosinase activity was slightly lower at $96.3 \% \pm 0.84 \%$.

The DPPH and ABTS radical scavenging activities decreased with a decrease in $\mathrm{RO}$ concentration (i.e., an increase in $100 \%$ SFE concentration; Figure 4(b)). The mixtures had higher scavenging activity for ABTS free radicals than DPPH free radicals. However, little difference was discovered in the $\mathrm{DPPH}$ and ABTS scavenging activities between the different extract mixtures; the maximum difference was approximately 6.2\%. Table 3 lists the antioxidant activity (reducing power, BCB activity, and FIC activity) and antioxidant capacity (TPC and TFC) of the $J$. sambac flower extracts at various mixture ratios. The results revealed that the $1: 9$ mixture ratio $\left(100 \%\right.$ SFE: $\mathrm{RO}$; V/V) had the lowest $\mathrm{IC}_{50}$ for reducing power and FIC activity but the highest $\mathrm{IC}_{50}$ in the BCB assay. Both TPC and TFC decreased with an increase in the $100 \%$ SFE content, indicating that $100 \%$ SFE contained fewer antioxidants. Even so, the TPC and TFC of all the mixtures were significantly greater (1.7-6.7 times) than those of J. sambac flower extracts obtained using acetone/water/ acetic acid solvent [30].

Figure 4(c) shows the effects of the mixture ratio on cell viability. When $100 \%$ SFE and RO were mixed in volume ratios $1: 9,2: 8,3: 7$, and $4: 6$, the $100 \%$ SFE and $\mathrm{RO}$ concentrations $(\mathrm{mg} / \mathrm{L})$ of the mixture solution were equivalent to 200 and 3,600; 400 and 3,200; 600 and 2,800; and 800 and 2,400, respectively. The results showed that the viability of CCD-966SK cells $(88.5 \% \pm 0.7 \%$ to $93.5 \% \pm 1.2 \%)$ and HEMn cells $(91.2 \% \pm 0.5 \%$ to $93.6 \% \pm 0.4 \%)$ was similar for all PCPs. Table 3 indicates that the $\mathrm{IC}_{50}$ for the reducing power, BCB activity, and FIC activity of various mixture extracts was $258 \pm 18.6$ to $324 \pm 12.8,456 \pm 34.1$ to $602 \pm 36.4$, and $394 \pm 32.1$ to $512 \pm 46.2 \mathrm{mg} / \mathrm{L}$, respectively. At these concentration ranges, the PCPs do not inhibit cell viability, even if $100 \%$ physiological activity is achieved. Thus, the PCPs are safe for commercial application.

\subsection{Chemical Compositions of J. sambac Flower Extracts and} the 2:8 Extract Mixture. To understand the physiological composition and aroma components, various J. sambac flower extracts were analyzed through GC-MS. Table 4 lists the detectable chemical components of the J. sambac flower extracts and 2:8 extract mixture. The results indicated that the number of chemical components in 5\%OE, $20 \% \mathrm{OE}$, $100 \%$ SFE, RO, and the $2: 8$ extract mixture was $45,39,29,38$, and 42 , respectively. These components generally belonged to three classes, namely, phenylpropanoid/benzenoid, terpenoid, and fatty acid esters; the result was in agreement with that of a previous report [10]. 5\%OE and 100\%SFE had the most and least chemical components, respectively. After the extraction process, the number of chemical components was lower. The main components $(>2 \%)$ of the products $(5 \%$ 

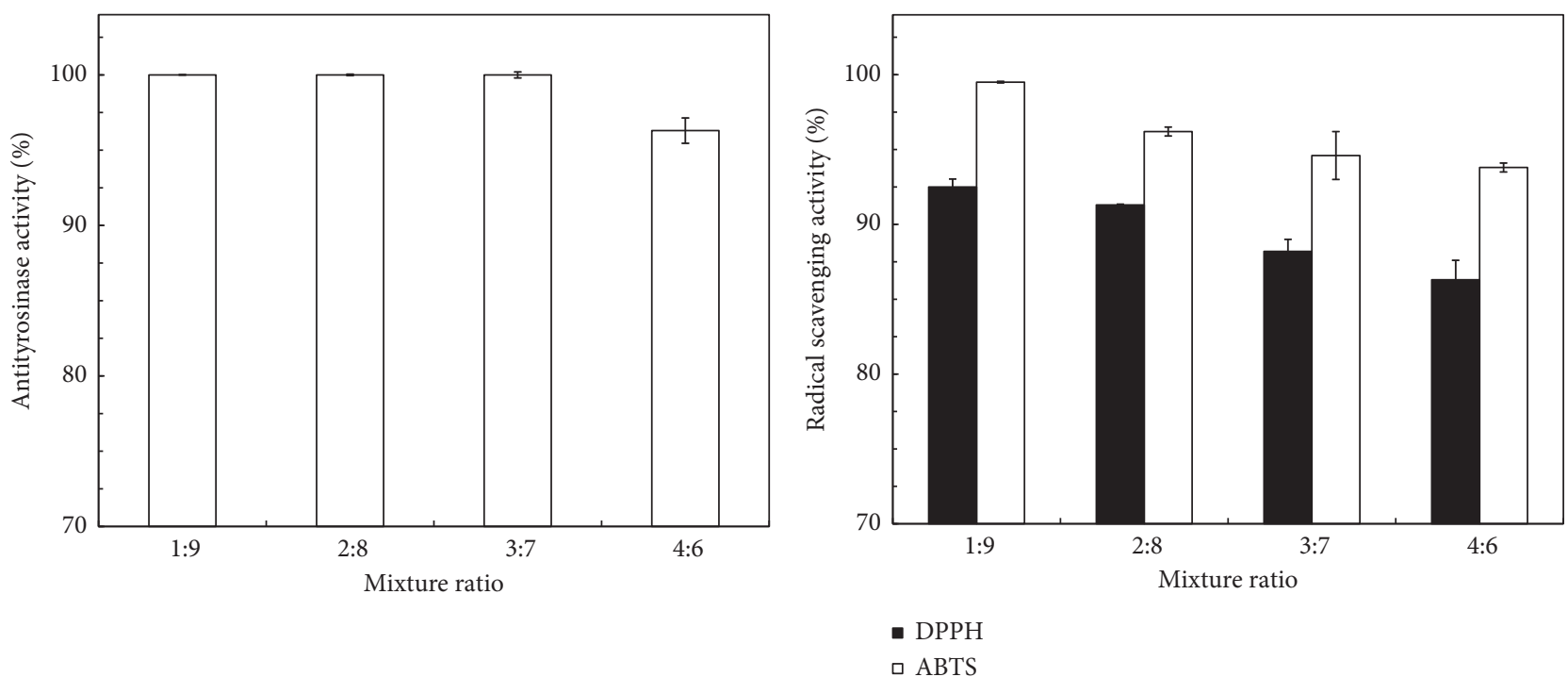

(a)

(b)

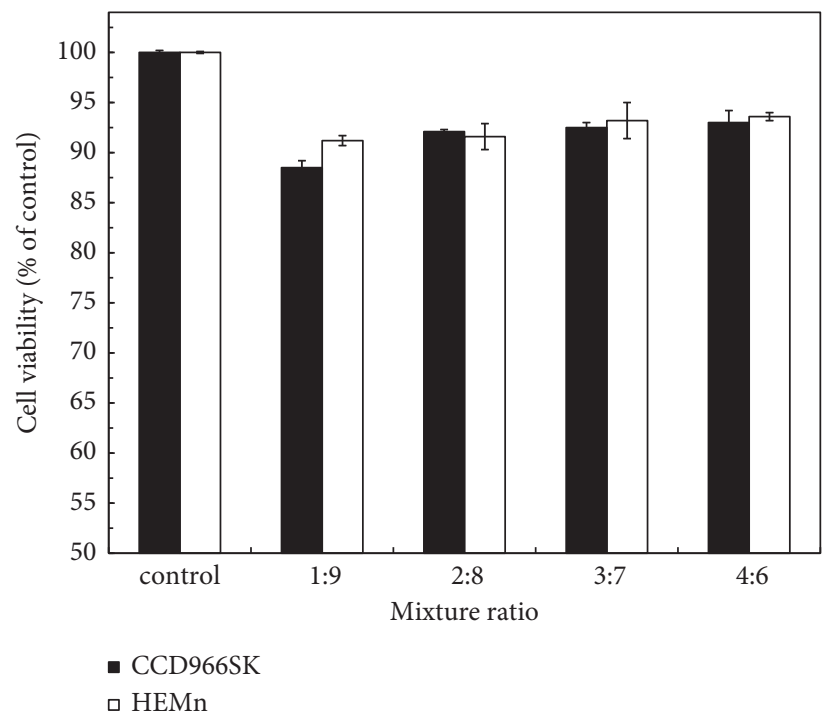

(c)

FiguRE 4: Effects of mixture ratio of J. sambac flower extracts on (a) antityrosinase activity, (b) radical scavenging activity, and (c) cell viability. The potential commercial product was produced by mixing 2,000 mg/L $100 \% \mathrm{SFE}$ and 4,000 $\mathrm{mg} / \mathrm{L} \mathrm{RO}$ at various ratios. Data are expressed as the means \pm standard deviations of 3 independent experiments.

TABLE 3: Antioxidant activity (reducing power, $\beta$-carotene bleaching assay, and ferrous-chelating activity) and antioxidant capacity (TPC and TFC) of $J$. sambac flower extracts at various mixture ratios.

\begin{tabular}{|c|c|c|c|c|}
\hline & $1: 9^{*}$ & $2: 8$ & $3: 7$ & $4: 6$ \\
\hline Reducing power, $\mathrm{IC}_{50}(\mathrm{mg} / \mathrm{L})$ & $258 \pm 18.6$ & $273 \pm 24.2$ & $306 \pm 30.1$ & $324 \pm 12.8$ \\
\hline$\beta$-Carotene bleaching assay, $\mathrm{IC}_{50}(\mathrm{mg} / \mathrm{L})$ & $602 \pm 36.4$ & $547 \pm 20.8$ & $512 \pm 16.5$ & $456 \pm 34.1$ \\
\hline $\mathrm{Fe}(\mathrm{II})$ chelating activity, $\mathrm{IC}_{50}(\mathrm{mg} / \mathrm{L})$ & $394 \pm 32.1$ & $421 \pm 38.5$ & $466 \pm 32.8$ & $512 \pm 46.2$ \\
\hline TPC (mg-gae/g) & $180.43 \pm 10.36$ & $172.15 \pm 8.75$ & $163.89 \pm 12.74$ & $138.95 \pm 7.87$ \\
\hline TFC (mg-cae/g) & $10.02 \pm 0.92$ & $9.17 \pm 1.24$ & $8.35 \pm 0.63$ & $7.54 \pm 0.83$ \\
\hline
\end{tabular}

${ }^{*}$ The PCP was produced by mixing 2,000 mg/L $100 \%$ SFE and 4,000 mg/L RO at various mixture ratios.

OE and 20\%OE) of $J$. sambac flower extracts obtained using an oil solvent were benzyl acetate, $\beta$-pinene, hexadecan-1-ol, 9,12,15-octadecatrienoic acid, citronellol, octacosane, squalene, floridanine, and jasminolactone. Among them, the content of jasminolactone $(17.14 \%-19.29 \%)$, floridanine $(9.96 \%-10.59 \%)$, and citronellol $(6.10 \%-8.94 \%)$ was 
TABLE 4: Chemical composition of J. sambac flower extracts and the 2:8 mixture.

\begin{tabular}{|c|c|c|c|c|c|c|}
\hline Retention time (min) & Chemical compounds & $5 \% \mathrm{OE}$ & $20 \% \mathrm{OE}$ & $100 \%$ SFE & $\mathrm{RO}$ & Mixture \\
\hline 7.935 & Benzyl acetate & 3.08 & 3.2 & 6.18 & 4.18 & 3.78 \\
\hline 8.240 & Limonene & 1.5 & 1.14 & 1.12 & 1.89 & 1.32 \\
\hline 24.056 & Methyl salicylate & 0.69 & 0.58 & - & - & 0.54 \\
\hline 24.158 & n-Dodecane & 1.43 & 1.36 & 1.58 & 0.66 & 1.23 \\
\hline 24.482 & 3,7,11,15-Tetramethyl-1-Hexadecen-3-ol & 0.96 & - & - & 0.8 & - \\
\hline 24.819 & 3,7,11-Trimethyl-1,6,10-dodecatrien-3-ol & 0.89 & - & - & 0.81 & 0.66 \\
\hline 24.934 & Germacrene D & 1.1 & 0.84 & 1.10 & 0.90 & 0.85 \\
\hline 25.106 & Benzyl alcohol & 0.6 & - & - & 0.68 & - \\
\hline 26.340 & Linalool & 0.79 & - & 1.12 & - & 0.71 \\
\hline 26.925 & Decane & 0.67 & 0.81 & 1.03 & - & 0.68 \\
\hline 27.008 & $\alpha$-Cadinol & 1.07 & 1.05 & - & 0.81 & 0.88 \\
\hline 27.167 & $\beta$-Elemene & 1.48 & 1.54 & - & - & 1.26 \\
\hline 27.205 & 2-Phenyl ethyl acetate & 0.84 & 0.84 & 1.27 & - & 0.76 \\
\hline 27.313 & $\beta$-Pinene & 3.11 & 4.63 & 5.03 & 1.89 & 3.09 \\
\hline 27.409 & Geraniol & 0.95 & 1.00 & 1.20 & 0.63 & 0.84 \\
\hline 27.676 & Geranyl acetate & 1.41 & 1.18 & 1.48 & 0.87 & 1.11 \\
\hline 27.784 & $\beta$-Caryophyllene & 1.39 & 0.85 & 1.02 & 0.85 & 0.79 \\
\hline 27.841 & Pentadecyl-2-propyl ester & 1.45 & 1.66 & 2.06 & 0.75 & 1.42 \\
\hline 28.013 & Farnesol & 1.87 & 1.23 & 1.51 & 1.67 & 1.18 \\
\hline 28.115 & Eugenol & 0.87 & - & - & 0.95 & - \\
\hline 28.280 & $\beta$-Sitosterol & 0.84 & - & - & 0.95 & 0.68 \\
\hline 28.414 & Palmitic acid & 0.93 & 0.67 & - & 0.86 & 0.71 \\
\hline 28.605 & Hexadecan-1-ol & 2.61 & 3.38 & 2.99 & 1.59 & 2.96 \\
\hline 29.018 & 9,12,15-Octadecatrienoic acid methyl ester & 1.15 & 1.58 & 1.73 & 1.00 & 1.31 \\
\hline 29.565 & Linoleic acid & - & 1.15 & 1.15 & 0.64 & - \\
\hline 29.623 & Phytol & 1.03 & 1.46 & 1.44 & 0.96 & 1.21 \\
\hline 29.718 & Tricosane & 0.87 & - & - & 1.16 & 0.95 \\
\hline 29.724 & Octadecanoic acid methyl ester & - & 1.21 & 1.12 & - & - \\
\hline 29.782 & Oleic acid & 1.06 & 1.42 & - & - & 0.89 \\
\hline 30.017 & 3,7,11,15-Tetramethyl-1-hexadecen-3-ol & 0.76 & 1.38 & - & 0.75 & 0.62 \\
\hline 30.138 & 9,12,15-Octadecatrienoic acid & 2.82 & 4.10 & 4.37 & 2.84 & 2.97 \\
\hline 30.857 & Nerolidol & 1.98 & 1.84 & 2.20 & - & 1.64 \\
\hline 31.448 & Pentadecane & 1.07 & 0.72 & - & 1.86 & 0.93 \\
\hline 31.913 & Citronellol & 6.10 & 8.94 & 8.47 & 5.37 & 7.85 \\
\hline 33.764 & Heptadecane & 1.20 & 1.32 & 1.89 & 1.98 & 1.33 \\
\hline 33.974 & Octacosane & 2.17 & 2.13 & 1.00 & - & 1.15 \\
\hline 36.926 & Jasmone & 1.46 & 1.2 & 1.46 & 2.64 & 1.42 \\
\hline 40.184 & Nonadecane & 1.06 & 0.99 & 1.57 & 2.01 & 1.47 \\
\hline 42.111 & $\alpha$-Farnesene & 1.56 & 0.90 & 1.31 & 2.04 & 1.31 \\
\hline 43.536 & Linalyl $\beta$-D-glucopyranoside & 0.9 & 0.76 & - & 1.51 & 0.81 \\
\hline 44.147 & Jasminol & 0.75 & - & - & 1.17 & 0.71 \\
\hline 44.236 & Tetratetracontane & 0.56 & 0.74 & - & 1.31 & 0.88 \\
\hline 44.707 & 1-Hentriacontanol & 0.53 & 0.45 & - & 2.15 & 1.14 \\
\hline 46.355 & Eicosane & 0.78 & 0.89 & - & 0.66 & 1.17 \\
\hline 46.876 & Squalene & 7.61 & 1.15 & 1.11 & 11.07 & 1.98 \\
\hline 52.640 & Floridanine & 9.96 & 10.59 & 22.52 & 13.86 & 17.63 \\
\hline 55.630 & Jasminolactone & 17.14 & 19.29 & 16.91 & 16.35 & 15.53 \\
\hline
\end{tabular}

relatively high. Furthermore, a similar composition was found when J. sambac flowers were extracted through enfleurage [3].

The main components $(>2 \%)$ of $100 \%$ SFE were benzyl acetate $(6.18 \%), \beta$-pinene (5.03\%), pentadecyl-2-propyl ester (2.06\%), 9,12,15-octadecatrienoic acid (4.37\%), hexadecan1-ol (2.99\%), nerolidol (2.20\%), citronellol (8.47\%), floridanine $(22.52 \%)$, and jasminolactone (16.91\%). The amounts of hydrophobic or volatile fragrance components in $100 \%$ SFE-such as linalool, 2-phenyl ethyl acetate, geranyl acetate, $\beta$-caryophyllene, farnesol, jasmone, and pentadecyl-2- propyl ester-were high compared with those in $20 \% \mathrm{OE}$, indicating the nature of the SFE- $\mathrm{CO}_{2}$ technique [17]. Among them, benzyl acetate produces a strong jasmine aroma, and other flavors such as citronellol, farnesol, linalool, and jasmone are famous fragrance ingredients used in perfumes, cosmetics, and household products [35,36]. Moreover, citronellol, farnesol, and geranyl acetate were detected in Pakistan J. sambac flower extracts obtained using the SFE$\mathrm{CO}_{2}$ technique [11]. Furthermore, benzyl acetate, linalool, and $\beta$-caryophyllene were present in China J. sambac flower extracts obtained using the SFE-diether methyl ester 
TABLE 5: Sensory evaluation and fragrance quality of $J$. sambac flower extracts at different mixture ratios analyzed through GC-MS.

\begin{tabular}{|c|c|c|c|c|}
\hline & $1: 9$ & $2: 8$ & $3: 7$ & $4: 6$ \\
\hline Sensory evaluation of fragrance & Regular & Good & Very good & Very good \\
\hline Levels of fragrance analyzed by GC-MS & Low & Acceptable & Acceptable & High \\
\hline Number of major fragrance composition by GC-MS & 9 & 18 & 21 & 26 \\
\hline
\end{tabular}

technique [12]. Linalool, benzyl acetate, and $\beta$-caryophyllene were found in China J. sambac flower extracts obtained using the SFE-petroleum ether technique [10].

After the SFE procedure, the types of chemical components in $\mathrm{RO}$ were similar to those in $20 \% \mathrm{OE}$. This was reasonable because both $100 \%$ SFE and RO were derived from $20 \% \mathrm{OE}$. Partial antioxidant ingredients were found only in RO but not in 100\%SFE; they included 3,7,11,15-tetramethyl-1-hexadecen3-ol, 3,7,11-trimethyl-1,6,10-dodecatrien-3-ol, $\quad \alpha$-cadinol, 3,7,11,15-tetramethyl-1-hexadecen-3-ol, benzyl alcohol, eugenol, $\beta$-sitosterol, jasminol, linalyl- $\beta$-D-glucopyranoside, and 1hentriacontanol. Thus, the antioxidant activity of RO was much higher than that of $100 \%$ SFE. The relevant results are presented in Figures 1 and 2 and Tables 1 and 2. The number of different chemical components in the $2: 8$ extract mixture was higher than that in the pure J. sambac flower extracts except for $5 \% \mathrm{OE}$. The ingredients in the 2:8 extract mixture contained both antioxidants with a hydroxyl functional group and volatile fragrance components, similar to the ingredients of natural J. sambac flower extracts [2,5]. Additionally, palmitic acid, linoleic acid, and oleic acid are almost never found in J. sambac flower extracts, and they may originate from the extracted solvent-that is, mustard oil [37]. The types and amounts of antioxidant constituents in the RO and 100\%SFE appropriately explained and reflected the antioxidant activity findings presented in previous sections.

3.8. Sensory Evaluation. Because the flavor and fragrance of commercial products are critical, sensory evaluation is always required [38]. Table 5 lists the results of the sensory and fragrance quality evaluations for the J. sambac flower extracts at different mixture ratios (100\%SFE to RO) analyzed through GC-MS. The results clearly indicated that the higher the proportion of $100 \%$ SFE within the solution, the stronger the fragrance. This may have been due to the high volatility of the flavor content in the extract mixture [3]. The 2:8 extract mixture exhibited a moderately intense, fresh, and jasmine-like flavor. Regarding the content percentage of fragrant compounds in the various extract mixtures, the content of the $2: 8$ extract mixture was classified as acceptable (42.6\%), whereas that of the 4:6 mixture was classified as high (51.3\%) due to the accumulation of fragrance components. Furthermore, the $2: 8$ and $4: 6$ extract mixtures contained 18 and 26 flavor components, respectively. Considering overall physiological activity, cytotoxicity, flavor acceptability, and product cost, the 2 : 8 jasmine extract mixture was identified as the optimal commercial product.

\section{Conclusion}

Our study is the first to provide detailed characteristics of commercial products obtained from J. sambac flower extract mixtures with a combination of fragrance and multifunctional physiological activities. RO was mostly composed of antioxidant ingredients with strong antityrosinase activity, high antioxidant activity, and slight cytotoxicity. By contrast, $100 \%$ SFE was composed of few antioxidant ingredients but abundant flavor compounds (e.g., benzyl acetate, citronellol, farnesol, linalool, and jasmone) compared with other J. sambac flower extracts, resulting in relatively low physiological activities, strong aroma, and noncytotoxicity. Considering the advantages and disadvantages of both, $100 \%$ SFE and RO were mixed in the ratio $2: 8$, and the resultant mixture exhibited satisfactory multifunctional physiological activities, noncytotoxicity, and moderately intense jasmine-like flavor and was economical. Similar products have not been reported in the literature or exist in the market. Thus, we strongly suggest that the $2: 8$ extract mixture derived from J. sambac flowers is a powerful antioxidant and whitening ingredient that can be employed in the food, cosmeceutical, and even pharmaceutical industries.

\section{Data Availability}

The datasets generated and analyzed during the current study are available from the corresponding author upon reasonable request.

\section{Conflicts of Interest}

The authors indicate no potential conflicts of interest.

\section{Authors' Contributions}

Li-Chun Wu and Chieh-Li Lin contributed equally to this work.

\section{Acknowledgments}

This research was supported by the Ministry of Science and Technology of Taiwan, grant numbers MOST 109-2313-B157-001- and MOST 109-2622-E-157-001-.

\section{References}

[1] K. M. Khidzir, S.-F. Cheng, and C.-H. Chuah, "Interspecies variation of chemical constituents and antioxidant capacity of extracts from Jasminum sambac and Jasminum multiflorum grown in Malaysia," Industrial Crops and Products, vol. 74, pp. 635-641, 2015.

[2] P. Bera, J. N. R. Kotamreddy, T. Samanta, S. Maiti, and A. Mitra, "Inter-specific variation in headspace scent volatiles composition of four commercially cultivated jasmine flowers," Natural Product Research, vol. 29, no. 14, pp. 1328-1335, 2015. 
[3] M. Kanlayavattanakul, S. Kitsiripaisarn, and N. Lourith, "Aroma profiles and preferences of Jasminum sambac L. flowers grown in Thailand," Journal of Cosmetic Science, vol. 64, pp. 483-493, 2013.

[4] S. Prabuseenivasan, M. Jayakumar, and S. Ignacimuthu, "In vitro antibacterial activity of some plant essential oils," $B M C$ Complementary and Alternative Medicine, vol. 6, no. 1, p. 39, 2006.

[5] Y. Yu, S. Lyu, D. Chen et al., "Volatiles emitted at different flowering stages of Jasminum sambac and expression of genes related to $\alpha$-farnesene biosynthesis," Molecules, vol. 22, no. 4, p. 546, 2017.

[6] S. Sushant and M. P. Prasad, "Physico-chemical characteristics and antioxidant assay of tomato (Lycopersicon esculentum Mill.) germplasm available in the south western region of Bangladesh," International Journal of Biosciences, vol. 6, no. 9, pp. 26-33, 2015.

[7] W. Widowati, W. Janeva, S. Nadya et al., "Antioxidant and antiaging activities of Jasminum Sambac extract, and its compounds," Journal of Reports in Pharmaceutical Sciences, vol. 7, pp. 270-285, 2018.

[8] P. Kunhachan, C. Banchonglikitkul, T. Kajsongkram, A. Khayungarnnawee, and W. Leelamanit, "Chemical composition, toxicity and vasodilatation effect of the flowers extract of Jasminum sambac (L.) Ait. "G. Duke of Tuscany"” Evidence-Based Complementary and Alternative Medicine, vol. 2012, Article ID 471312, 4 pages, 2012.

[9] V. S. Pragadheesh, A. Yadav, C. S. Chanotiya, P. K. Rout, and G. C. Uniyal, "Monitoring the emission of volatile organic compounds from flowers of Jasminum sambac using solidphase micro-extraction fibers and gas chromatography with mass spectrometry detection," Natural product communications, vol. 6, no. 9, pp. 1333-1338, 2011.

[10] Q. Ye, X. Jin, S. Wei, G. Zheng, and X. Li, "Effect of subcritical fluid extraction on the high quality of headspace oil from Jasminum sambac (L.) Aiton," Journal of AOAC International, vol. 99, no. 3, pp. 725-729, 2016.

[11] A. Younis, A. Mehdi, and A. Riaz, "Supercritical carbon dioxide extraction and gas chromatography analysis of Jasminum sambac essential oil," Pakistan Journal of Botany, vol. 43, pp. 163-168, 2011.

[12] Q. Ye, X. Jin, X. Zhu, T. Lin, Z. Hao, and Q. Yang, “An efficient extraction method for fragrant volatiles from Jasminum sambac (L.) Ait," Journal of Oleo Science, vol. 64, no. 6, pp. 645-652, 2015.

[13] P. R. Bharathi, S. K. Sripathi, and A. N. Lakshmi, "Jasminum grandiflorum linn.-an update review," International Journal of Pharmaceutical Sciences and Research, vol. 11, pp. 1994-2010, 2020.

[14] P. Bera, C. Mukherjee, and A. Mitra, "Enzymatic production and emission of floral scent volatiles in Jasminum sambac," Plant Science, vol. 256, pp. 25-38, 2017.

[15] S. Sabharwal, S. Sudan, and V. Ranjan, "Jasminum sambac Linn. (Motia): a review," International Journal of Pharma Bio Sciences, vol. 2, pp. 108-130, 2013.

[16] H. H. Rassem, A. H. Nour, R. M. Yunus, Y. H. Zaki, and H. S. M. Abdlrhman, "Yield optimization and supercritical CO2 extraction of essential oil from jasmine flower," Indonesian Journal of Chemistry, vol. 19, no. 2, pp. 479-485, 2019.

[17] T. Arumugham, P. L. Show, J. Rinklebe, and F. Banat, "Supercritical carbon dioxide extraction of plant phytochemicals for biological and environmental applications-a review," Chemosphere, vol. 271, Article ID 129525, 2021.
[18] G.-H. Wang, Y.-M. Lin, J.-T. Kuo et al., "Comparison of biofunctional activity of Asparagus cochinchinensis (Lour.) Merr. Extract before and after fermentation with Aspergillus oryzae," Journal of Bioscience and Bioengineering, vol. 127, no. 1, pp. 59-65, 2019.

[19] L. Wu, C. Chen, C. Cheng et al., "Evaluation of tyrosinase inhibitory, antioxidant, antimicrobial, and antiaging activities of Magnolia officinalis extracts after Aspergillus niger fermentation," BioMed Research International, vol. 2018, Article ID 5201786, 11 pages, 2018.

[20] K. H. Lee, Y. Chun, Y. W. Jang et al., "Fabrication of functional bioelastomer for food packaging from aronia (Aronia melanocarpa) juice processing by-products," Foods, vol. 9, no. 11, p. 1565, 2020.

[21] S. Fejes, A. Blázovics, A. Lugasi, É. Lemberkovics, G. Petri, and Á. Kéry, "In vitro antioxidant activity of Anthriscus cerefolium L. (Hoffm.) extracts," Journal of Ethnopharmacology, vol. 69, no. 3, pp. 259-265, 2000.

[22] W. C. Lee, R. Mahmud, S. Pillai, S. Perumal, and S. Ismail, "Antioxidant activities of essential oil of Psidium guajava L. leaves," APCBEE Procedia, vol. 2, pp. 86-91, 2012.

[23] N. Echegaray, P. E. S. Munekata, J. A. Centeno et al., "Total phenol content and antioxidant activity of different celta pig carcass locations as affected by the finishing diet (chestnuts or commercial feed)," Antioxidants, vol. 10, no. 1, p. 5, 2020.

[24] W.-T. Liao, T.-S. Huang, C.-C. Chiu et al., "Biological properties of acidic cosmetic water from seawater," International Journal of Molecular Sciences, vol. 13, no. 5, pp. 5952-5971, 2012.

[25] Y. Wang, C. M. Zhao, T. Guo, Y. L. Zhu, and P. Y. Zhao, "Preliminary screening of 44 plant extracts for anti-tyrosinase and antioxidant activities," Pakistan Journal of Pharmaceutical Sciences, vol. 28, pp. 1737-1744, 2015.

[26] R. Meccariello and S. D’Angelo, "Impact of polyphenolic-food on longevity: an elixir of life. An overview," Antioxidants, vol. 10 , no. 4 , p. $507,2021$.

[27] F. Takahiro, A. Hisae, and K. Ken, "Antioxidant property of fullerene is effective in skin whitening," Journal of the American Academy of Dermatology, vol. 62, no. 3, p. AB54, 2010.

[28] R. A. El-Shiekh, F. R. Saber, and E. A. Abdel-Sattar, "In vitro anti-hypertensive activity of Jasminum grandiflorum subsp. floribundum (Oleaceae) in relation to its metabolite profile as revealed via UPLC-HRMS analysis," Journal of Chromatography $B$, vol. 1158, p. 122334, 2020.

[29] B. Xu and S. K. C. Chang, "Total phenolic, phenolic acid, anthocyanin, flavan-3-ol, and flavonol profiles and antioxidant properties of pinto and black beans (Phaseolus Vulgaris L.) as affected by thermal processing," Journal of Agricultural and Food Chemistry, vol. 57, no. 11, pp. 4754-4764, 2009.

[30] J. Zheng, X. Yu, M. Maninder, and B. Xu, "Total phenolics and antioxidants profiles of commonly consumed edible flowers in China," International Journal of Food Properties, vol. 21, no. 1, pp. 1524-1540, 2018.

[31] R. Amarowicz and R. B. Pegg, "Natural antioxidants of plant origin," Advances in Food \& Nutrition Research, vol. 90, pp. 1-81, 2019.

[32] I. Navarro-González, R. González-Barrio, V. García-Valverde, A. Bautista-Ortín, and M. Periago, "Nutritional composition and antioxidant capacity in edible flowers: characterisation of phenolic compounds by HPLC-DAD-ESI/MSn," International Journal of Molecular Sciences, vol. 16, no. 1, pp. 805822, 2014. 
[33] J. van Meerloo, G. J. L. Cloos, and J. Cloos, "Cell sensitivity assays: the MTT assay," Methods in Molecular Biology, vol. 731, pp. 237-245, 2011.

[34] A. V. B. Pintor, L. D. Queiroz, R. Barcelos, L. S. G. Primo, L. C. Maia, and G. G. Alves, "MTT versus other cell viability assays to evaluate the biocompatibility of root canal filling materials: a systematic review," International Endodontic Journal, vol. 53, no. 10, pp. 1348-1373, 2020.

[35] A. E. Edris, R. Chizzola, and C. Franz, "Isolation and characterization of the volatile aroma compounds from the concrete headspace and the absolute of Jasminum sambac (L.) Ait. (Oleaceae) flowers grown in Egypt," European Food Research and Technology, vol. 226, no. 3, pp. 621-626, 2008.

[36] H.-C. Zhou, Z.-W. Hou, D.-X. Wang, J.-M. Ning, and S. Wei, "Large scale preparation, stress analysis, and storage of headspace volatile condensates from Jasminum sambac flowers," Food Chemistry, vol. 286, pp. 170-178, 2019.

[37] H. E. Embaby, R. A. Habiba, A. A. Shattab, M. M. ElHamamy, N. Morita, and S. S. Ibrahim, "Chemical composition and stability of canola oils from Japan and Egypt," Agricultural Research Journal, vol. 6, pp. 13-19, 2006.

[38] L. Balcerzak, J. Gibka, M. Sikora, J. Kula, and D. J. Strub, "Minor constituents of essential oils and aromatic extracts. Oximes derived from natural flavor and fragrance raw materials - sensory evaluation, spectral and gas chromatographic characteristics," Food Chemistry, vol. 301, Article ID 125283, 2019. 